\title{
Padronização das técnicas de secção do nervo facial e de avaliação da mímica facial em ratos
}

\author{
Simone Damasceno de Faria ${ }^{1}$, José Ricardo Gurgel \\ Testa $^{2}$, Andrei Borin ${ }^{3}$, Ronaldo N. Toledo
}

\section{Resumo / Summary}

$\mathrm{O}$

bjetivo: Padronização da técnica de secção do nervo facial extratemporal em ratos e elaboração de uma escala de avaliação da mímica facial desses animais antes e após essa secção. Tipo de Estudo: Experimental. Método: Vinte ratos Wistar foram anestesiados com xilasina e ketamina e submetidos à secção do nervo facial próximo à sua emergência pelo forame mastóideo na pele. Todos os animais foram avaliados. Foram observados: fechamento ocular, reflexo de piscamento, movimentação e posicionamento das vibrissas, e foi elaborada uma escala de avaliação e graduação destes parâmetros. Resultados: O tronco do nervo facial foi encontrado entre a margem tendinosa do músculo clavotrapézio e a cartilagem auricular. $O$ tronco foi seccionado proximal à sua saída pelo forame mastóideo e os cotos foram suturados com nylon 9-0. Foi elaborada uma escala de avaliação e graduação da mímica facial independente para olho e vibrissa e a somatória dos parâmetros, como forma de avaliar a face paralisada. A ausência de piscamento e de fechamento ocular recebeu valor 1; a presença de contração do músculo orbicular, sem reflexo de piscamento, valor 2; fechamento ocular de 50\% através de reflexo de piscamento, valor 3 , o fechamento de $75 \%$, valor 4 . A presença de reflexo de piscamento com fechamento ocular completo recebeu valor 5 . A ausência de movimento e posição posterior das vibrissas recebeu pontuação 1; tremor leve e posição posterior, pontuação 2; tremor maior e posição posterior, pontuação 3 e movimento normal com posição posterior, pontuação 4. A movimentação simétrica das vibrissas, com posição anterior recebeu pontuação 5. Conclusão: O rato apresenta anatomia que permite fácil acesso ao nervo facial extratemporal, possibilitando secção e sutura desse nervo de forma padronizada. Também foi possível estabelecer uma escala de avaliação e graduação da mímica facial dos ratos com paralisia facial a partir da observação clínica desses animais.

\section{Standardization of techniques used in facial nerve section and facial movement evaluation in rats}

Palavras-chave: avaliação, cirurgia, nervo facial, paralisia facial, ratos.

Keywords: evaluation, surgery, facial nerve, facial palsy, rats.

Título de Especialista em ORL, Pós-graduanda nível mestrado ORL-UNIFESP

${ }^{2}$ Doutor em Medicina, Mestre - UNIFESP, Professor afiliado da Disciplina de Otorrinolaringologia Pediátrica da UNIFESP-EPM, Pós-graduando nível doutorado - UNIFESP

${ }^{3}$ Mestre em Ciências - UNIFESP, Pós-graduando nível doutorado.

${ }^{4}$ Mestre em Ciências - UNIFESP, Pós-graduando nível doutorado. Universidade Federal de São Paulo.

Endereço para correspondência: Simone Damasceno de Faria - Rua Jupiter 54 apto. 10 Aclimação São Paulo 01532-030.

Este artigo foi submetido no SGP (Sistema de Gestão de Publicações) da RBORL em 6 de dezembro de 2005.

Artigo aceito em 24 de março de 2006. 


\section{INTRODUÇÃO}

A paralisia facial decorrente de trauma ao nervo facial é uma condição clínica relativamente comum. Sua manifestação unilateral pode acarretar alteração da simetria facial, fechamento ocular incompleto com ou sem repercussão oftálmica, dificuldade de deglutição e de articulação de certos fonemas, entre outros problemas. Portanto, esta afecção traz conseqüências individuais e sociais relevantes, suscitando grande esforço na tentativa de compreender os diversos fatores que envolvem a lesão do nervo facial, sua regeneração e reparo, para assim amenizar essas conseqüências.

As fibras motoras do nervo facial, embora tenham origem no sistema nervoso central, possuem grande capacidade regenerativa, comparando-se a um nervo motor periférico. O nervo facial apresenta clearance de debris e de mielina maior do que o Sistema Nervoso Central (SNC) e possui uma espécie de guia para o processo regenerativo ao contrário do SNC. O nervo facial apresenta, ainda, maior capacidade de resposta aos fatores de crescimento após lesões ${ }^{1}$.

Após lesão, o axônio é influenciado por uma série de eventos, entre eles: fatores parácrinos locais, transporte retrógrado de moléculas (citocinas e fatores de crescimento), influxo de cálcio e sódio, geração de radicais livres, aumento da atividade das fosfolipases, geração de derivados de ácido aracdônico, fatores genéticos (equilíbrio entre bcl2 e bax/bak) ${ }^{1}$.

A degeneração walleriana, que segue a lesão neural, sofre influência destes fatores e se completa aproximadamente em trinta dias, levando a remoção de fragmento do axônio distal. No processo de regeneração, que tem início no primeiro nódulo de Ranvier próximo ao sítio da lesão e que apresenta taxa de crescimento de um a dois milímetros por dia, as células de Schwann têm papel fundamental (removem debris neuronais, secretam citocinas, fatores de crescimento); porém a integridade da membrana basal do endoneuro é necessária para guiar este processo ${ }^{1}$.

Assim sendo, o tipo de lesão a qual o nervo é submetido tem fundamental importância no processo de regeneração e na conduta a ser tomada. Sunderland classificou a lesão do nervo com base nos achados histológicos em: primeiro grau - estrutura do nervo intacta (neuropraxia), segundo grau - axônio rompido com células de Schwann integras (axonotmese), terceiro grau - lesão do endoneuro, quarto grau - lesão do perineuro e quinto grau - rotura completa (neurotmese). Nos dois primeiros graus de lesão geralmente ocorre recuperação completa do nervo e de sua capacidade funcional ${ }^{1}$. Porém, quando há perda de continuidade do nervo, o reparo direto do mesmo tem sido advogado como forma mais efetiva de reabilitação especificamente para o nervo facial. Quando isto não é viável são necessários os enxertos nervosos².
Embora a técnica cirúrgica venha se aprimorando, o resultado funcional associado ao reparo das lesões completas do nervo facial permanece insatisfatório ${ }^{1,2}$. Este fato vem impulsionando muitos estudos experimentais na tentativa de estabelecer a melhor abordagem ${ }^{2-4}$ e o tempo mais adequado de abordagem da lesão desse nervo ${ }^{5-8}$.

Outra vertente tem estudado substâncias que atuem na regeneração do nervo facial pós-trauma na tentativa de introduzir uma alternativa terapêutica que possa trazer melhores resultados funcionais, principalmente, nas paralisias decorrentes de secção completa do nervo facial. Entre essas substâncias estão os fatores neurotróficos ${ }^{9}$, os andrógenos ${ }^{10}$ e a nimodipina ${ }^{11}$.

Com o avanço da pesquisa experimental, muitos modelos animais têm sido utilizados (ratos, camundongos, coelhos, gatos). Porém não há uma padronização de modelo experimental para estudar a paralisia facial - avaliação comportamental, técnica de abordagem e lesão do nervo facial e início do processo regenerativo.

O estabelecimento de uma escala de avaliação da mímica facial e a padronização da técnica cirúrgica de abordagem do nervo facial e das etapas do seu processo regenerativo são de grande valia para o desenvolvimento de estudos de drogas sistêmicas que promovam melhor recuperação do nervo facial.

O objetivo deste estudo é padronizar a técnica de secção do nervo facial extratemporal em ratos e estabelecer uma escala de avaliação da mímica facial desses animais antes e após a secção desse nervo craniano.

\section{MÉTODO}

Vinte ratos adultos, Wistar, machos, pesando entre 250 e $300 \mathrm{~g}$, foram utilizados neste estudo. Os animais foram mantidos em sala adequada, com ciclo de 12 horas claro - 12 horas escuro. Alojados em gaiolas apropriadas, tiveram livre acesso à água e alimento. Todos os procedimentos foram realizados de acordo com as orientações do Comitê de Ética em Pesquisa do Hospital São Paulo - Universidade Federal de São Paulo (UNIFESP)

Esses ratos foram submetidos à anestesia com xilasina $2 \%(0,5 \mathrm{ml} / \mathrm{kg})$ e ketamina $10 \%(0,9 \mathrm{ml} / \mathrm{kg})$ intraperitoneal. A seguir foi feita tricotomia da região retroauricular direita. Então foram posicionados em decúbito lateral esquerdo e infiltrou-se xilocaína (repetida se necessário) nesta região, dando-se início ao procedimento cirúrgico que resultou na paralisia facial periférica direita destes animais. O procedimento foi realizado por dois cirurgiões, com a utilização de Microscópio cirúrgico DF-Vasconcellos M90, com lente de $200 \mathrm{~mm}$ e aumento de 16 vezes. Os resultados das cirurgias foram fotografados com câmera Sony Cybershot 3,2 e padronizados.

Todos os animais foram submetidos à observação da mímica facial, de forma espontânea e sob estímulo. Esta avaliação foi realizada pelo mesmo observador, e ocorreu 
previamente à cirurgia (para excluir alterações prévias na mímica facial que comprometessem avaliação posterior) e em dias alternados no pós-operatório, durante trinta dias. Os parâmetros observados foram: o fechamento ocular, o reflexo de piscamento, a movimentação e a posição das vibrissas. Para tanto, cada rato foi avaliado individualmente em uma caixa de papelão $(37 \times 21 \times 13 \mathrm{~cm})$ com a face interna de cor preta (maior clareza na observação das vibrissas), e como estímulo utilizou-se a insuflação de ar (seringa de $20 \mathrm{ml}$ ) na face do animal para desencadear o reflexo de piscamento e o bater de palmas das mãos (três a quatro) para desencadear maior movimentação das vibrissas. O lado esquerdo serviu como controle (reflexo de piscamento presente com fechamento ocular completo; movimentação das vibrissas presente e posicionamento anterior das mesmas). A partir dessa observação, foi elaborada uma escala de avaliação da mímica facial desses animais.

\section{RESULTADOS}

Com os animais adequadamente posicionados, iniciou-se a cirurgia. Após incisão retroauricular direita (cerca de três centímetros), procedeu-se a dissecção por planos. O músculo platisma foi identificado, superficialmente, e sua porção cranial foi seccionada. A margem tendinosa do músculo clavotrapézio foi encontrada junto à porção póstero-superior da incisão e o tronco do nervo facial foi localizado junto a essa margem, que foi afastada no sentido posterior para melhor visualização da emergência do nervo. Não houve necessidade de seccionar essa margem. Esse tronco foi seguido em sentido ântero-inferior até encontrar sua bifurcação, localizada medialmente à veia jugular externa e seus ramos. Os ramos do nervo facial, recobertos por fáscia, não foram dissecados.

O tronco do nervo facial foi então seccionado com

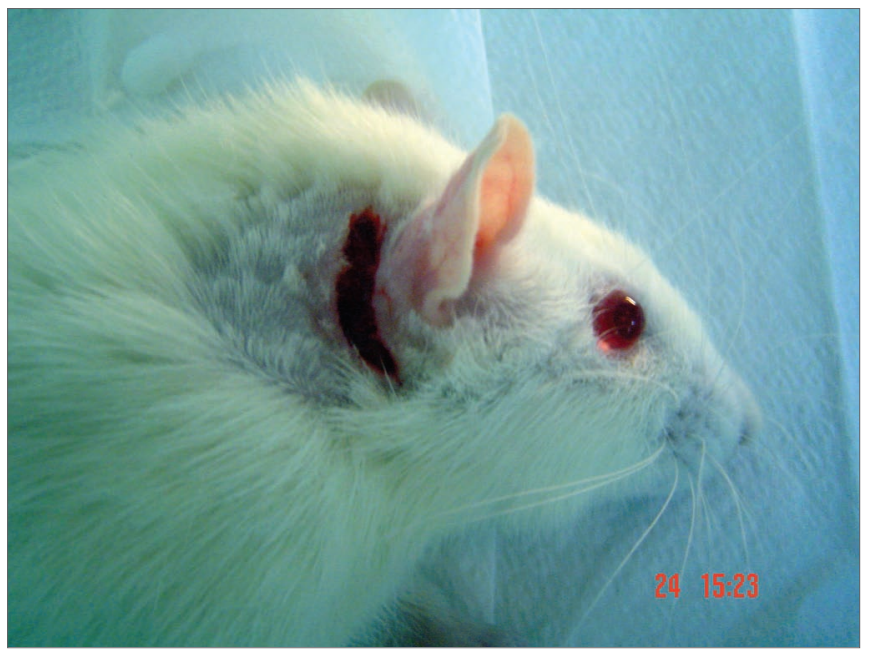

Figura 1. Incisão retroauricular na pele e subcutâneo. bisturi, proximal à sua emergência, e suturado com nylon 9.0. Utilizamos a aproximação dos cotos com um ponto. Em sete animais (35\%), um pequeno ramo divergia do tronco principal ainda junto ao forame mastóideo. Em quatro casos, realizamos a secção e sutura do tronco e do ramo, porém nos outros três conseguimos isolar o tronco principal e seccioná-lo.

Após a sutura epineural, procedeu-se ao fechamento da pele com pontos separados de nylon 4-0 cortados próximo à incisão. (Figuras 1 a 4)

Nenhum animal foi excluído do estudo. A partir da observação realizada após a secção e sutura do nervo facial, foi possível estabelecer uma escala de avaliação da mímica facial destes ratos. O fechamento ocular através do reflexo de piscamento e a movimentação das vibrissas foram observados e distribuídos separadamente em uma escala.

A presença de movimentação das vibrissas e seu posicionamento anterior, de forma simétrica ao lado controle, foram estabelecidos como sinal de recuperação funcional completa deste ramo do nervo facial do lado operado e recebeu pontuação 5. O reflexo de piscamento presente com fechamento ocular completo também recebeu pontuação 5. Portanto, a recuperação completa da hemiface direita recebeu valor 10, mesmo valor atribuído à mímica facial prévia à cirurgia (não foi observada recuperação completa em nenhum animal no período de trinta dias).

A ausência completa de reflexo de piscamento sem fechamento ocular recebeu pontuação 1, e a ausência de movimentação das vibrissas com posicionamento posterior, pontuação 1. Desta forma a paralisia facial completa recebeu valor 2 e foi vista em todos os ratos submetidos ao procedimento cirúrgico.

À presença de tremor leve das vibrissas com posição posterior, atribuiu-se valor 2 ; tremor maior com posição

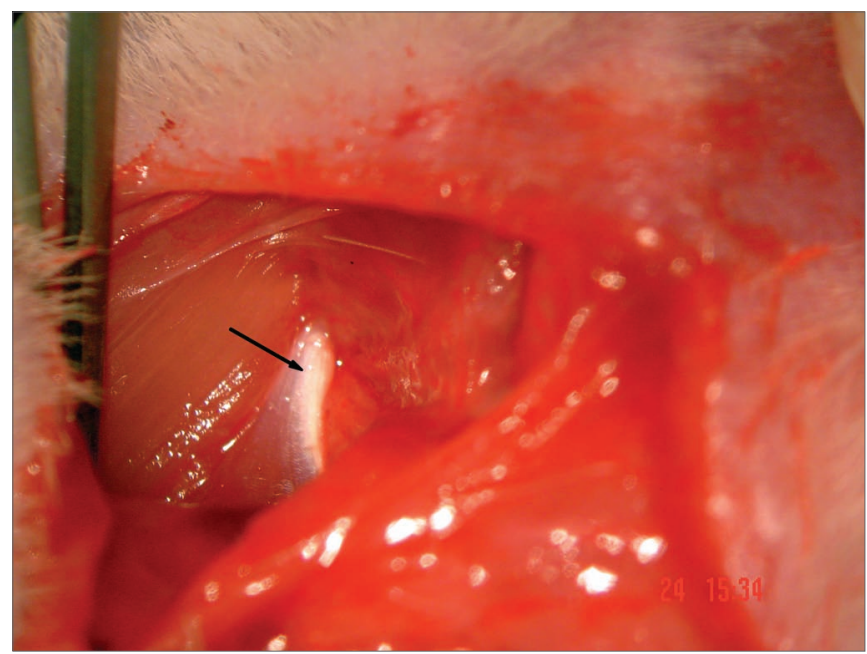

Figura 2. Margem tendionsa do músculo clavotrapézio - seta. 


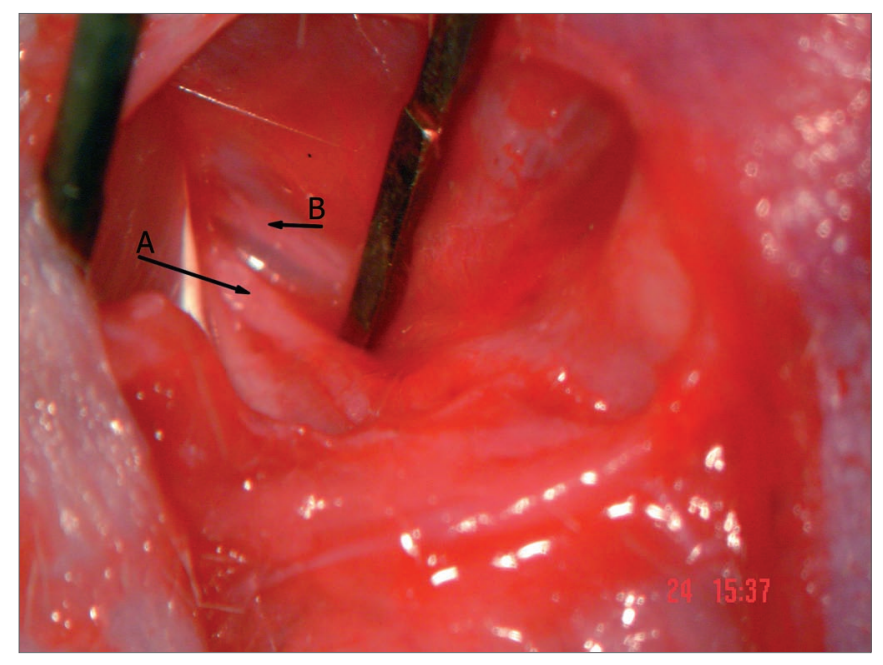

Figura 3. Tronco do nervo facial: tronco principal - seta A; ramo auricular posterior - seta B.

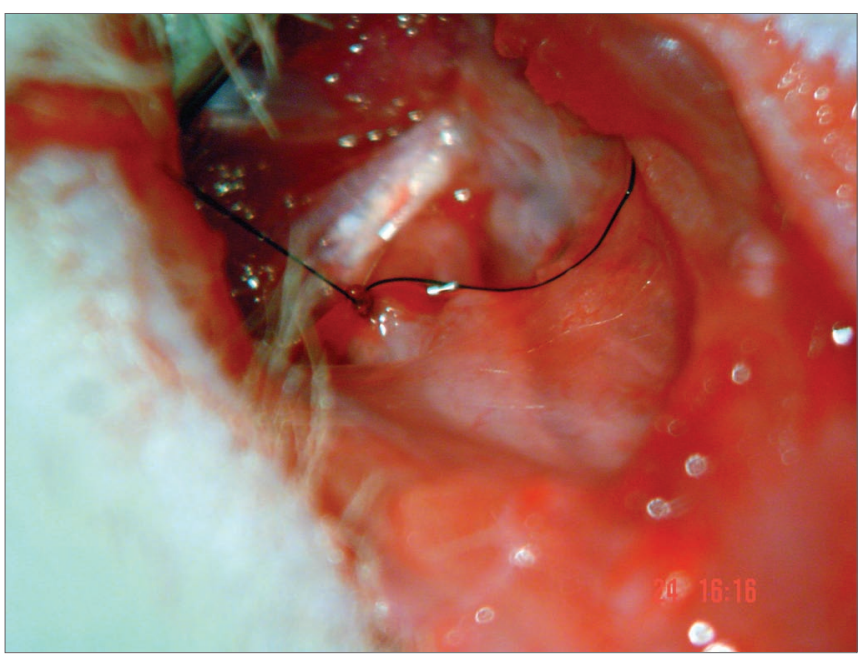

Figura 4. Aproximação dos cotos do nervo facial. nylon 9-0.

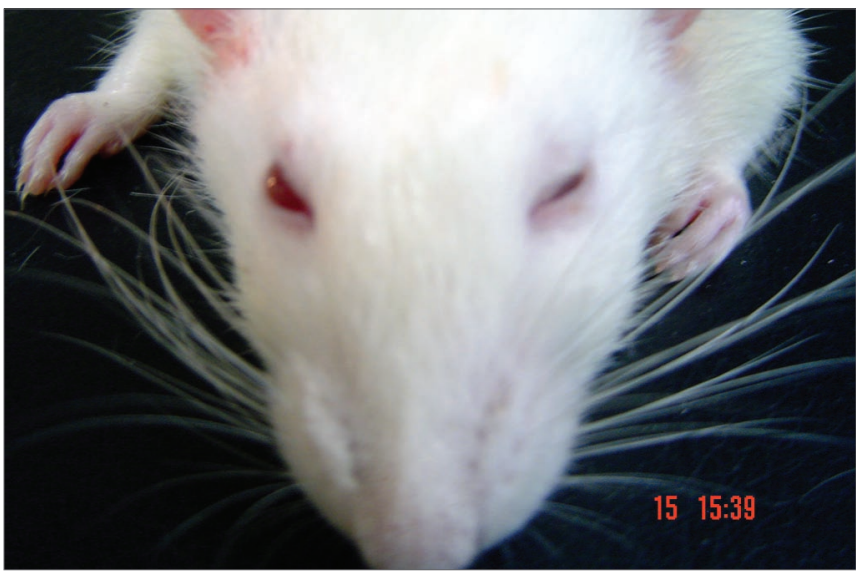

Figura 5. Avaliação sob estímulo no pós-operatório imediato: reflexo de piscamento presente com fechamento ocular completo e movimentação das vibrissas com posição anterior do lado esquerdo. À direita, ausência de movimentação ocular e das vibrissas que estão em posição posterior (1 ponto para as vibrissas e 1 para os olhos - lado direito).

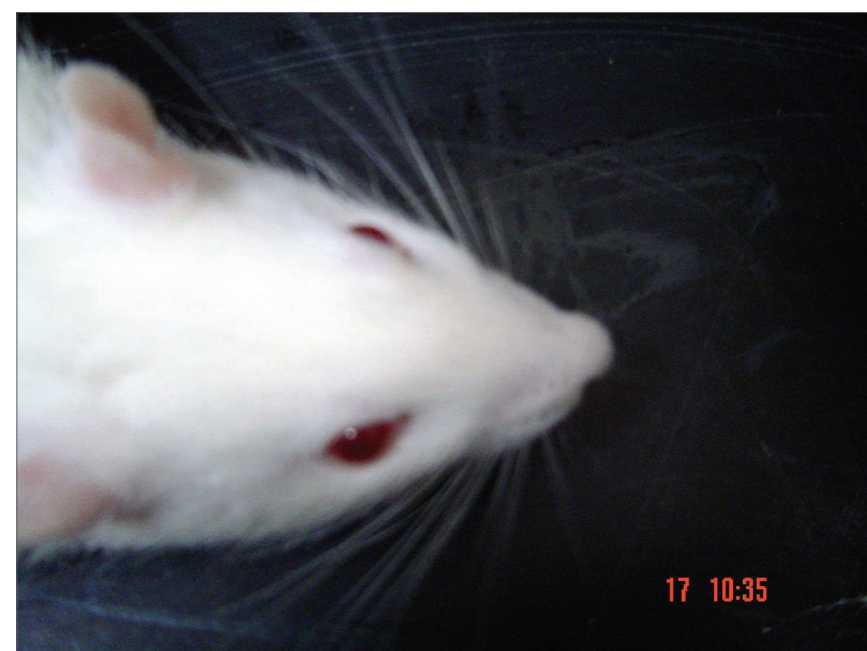

Figura 6. Avaliação espontânea antes da secção do nervo facial - vibrissas com movimentação simétrica e posição anterior (5 pontos).

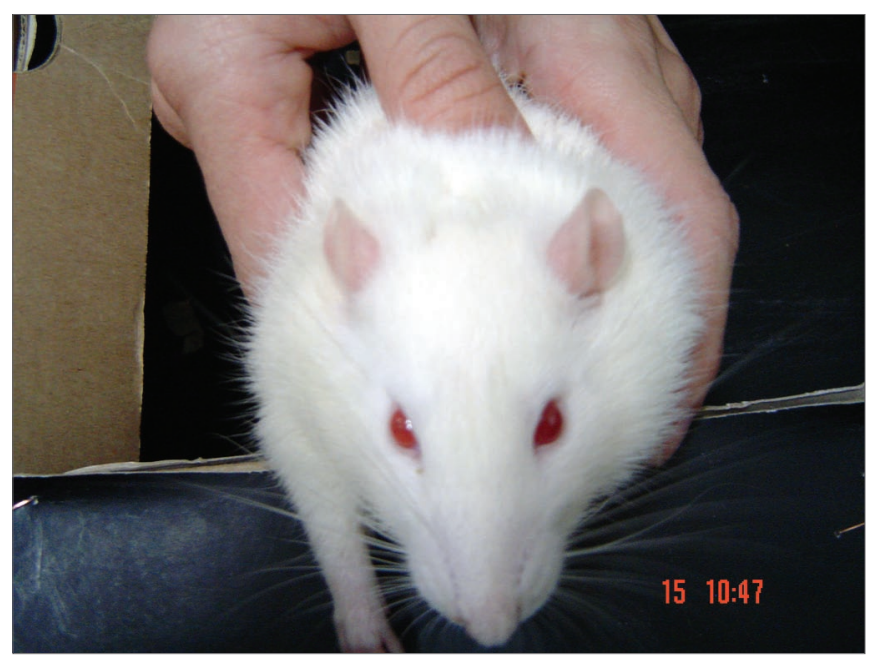

Figura 7. Animal apresentando movimentação normal das vibrissas e posição anterior, à esquerda (5 pontos); tremor maior das vibrissas e posição posterior, à direita (3 pontos).

e o trauma.

Em decorrência do grande impacto que sua disfunção provoca, o nervo facial vem sendo estudado em várias vertentes, tendo o estudo experimental papel chave neste processo.

Muitos animais têm sido utilizados com modelo experimental entre eles: coelho, porco, rato, camundongo, gato. Vários tipos de lesão do nervo facial são descritos nos trabalhos que abordam a paralisia facial, sendo o esmagamento e a secção desse nervo os tipos mais descritos. Porém, não se encontra um padrão estabelecido para a abordagem cirúrgica do nervo facial e para a observação da conseqüente paralisia facial nesses animais. Essa padronização daria uniformidade aos estudos com determinado animal e facilitaria a comparação de resultados.

Grande número de trabalhos tem utilizado o rato 
posterior das vibrissas recebeu pontuação 3 e o movimento normal das vibrissas mantendo posição posterior, pontuação 4 .

O reflexo de piscamento ausente (ausência de fechamento ocular) e a presença de contração do músculo orbicular receberam pontuação 2; o fechamento de metade (50\%) da fenda ocular com reflexo de piscamento presente recebeu valor 3 e o fechamento quase total (75\%) da fenda, valor 4 .

As escalas elaboradas foram representadas nos Quadros 1 e 2 a seguir:

A avaliação dos animais, através dessa escala, pode ser exemplificada nas fotografias que se seguem. (Figuras 5 a 7 ).

Quadro 1. Escala de observação das vibrissas.

\begin{tabular}{ccc}
\hline Pontuação & Movimento & Posição \\
\hline 1 & Sem movimento & posterior \\
2 & Tremor leve & posterior \\
3 & Tremor maior & posterior \\
4 & Movimento normal & posterior \\
\hline 5 & Movimento normal & anterior \\
\hline
\end{tabular}

Quadro 2. Escala de observação do fechamento ocular e reflexo de piscamento.

\begin{tabular}{cc}
\hline Pontuação & Movimento \\
\hline 1 & Sem movimento \\
2 & Contração/sem fechamento \\
3 & Fechamento de $50 \%$ \\
4 & Fechamento de $75 \%$ \\
5 & Fechamento completo \\
\hline
\end{tabular}

\section{DISCUSSÃOO}

A face humana pode ser considerada um espelho dos nossos sentimentos, pois através da movimentação de seus músculos expressamos diferentes tipos de emoções em diversos graus. Tem também fundamental participação na comunicação social por estar integrada ao processo de fala.

A integridade do nervo facial, responsável pela inervação dos músculos da mímica facial, apresenta papel relevante no contexto social e individual. Funções fisiológicas importantes dependem desta integridade, como o lacrimejamento e a proteção ocular, o gosto (dois terços anteriores da língua), a ingestão de alimentos (o músculo orbicular da boca toma parte no início do processo), a salivação, entre outras ${ }^{12}$. Várias são as causas desta disfunção, sendo as mais comuns os processos inflamatórios como modelo experimental por possuir vantagens como facilidade de aquisição e tolerância à paralisia facial, mesmo bilateral, sem apresentar problemas no período pós-operatório imediato ${ }^{13}$.

Os ratos utilizados neste estudo foram Wistar que, juntamente com os Sprague-Dawley, são freqüentemente usados.

Os animais foram submetidos à anestesia com xilasina a $2 \%(0,5 \mathrm{ml} / \mathrm{kg})$ e ketamina $10 \%(0,9 \mathrm{ml} / \mathrm{kg})$, intraperitoneal. Esta combinação é bastante utilizada para anestesiar tanto ratos como outros animais usados em estudos experimentais ${ }^{2,7,14-16}$.

A incisão retroauricular, utilizada neste estudo, permitiu boa exposição para a exploração do nervo facial, sendo referida com freqüência em trabalhos que descrevem com mais detalhes esta abordagem em $\operatorname{ratos}^{13,14} \mathrm{e}$ em outros animais ${ }^{12}$. Outra incisão também utilizada é a infra-auricular ${ }^{17,18}$.

O nervo facial pode ser abordado em seu trajeto intratemporal ${ }^{6,12,14}$, porém, optamos pela abordagem de seu trajeto extratemporal, próximo à sua emergência pelo forame mastóideo, por ser a forma mais comumente adotada pelos trabalhos que provocaram paralisia facial em ratos $2,3,16,19-21$.

Para encontrarmos a emergência do nervo facial pelo forame mastóideo seccionamos o músculo platisma e utilizamos como parâmetros a cartilagem auricular e a margem tendinosa do músculo clavotrapézio ${ }^{13,14}$. Dessa forma, localizamos o tronco principal do nervo facial entre a cartilagem auricular, anteriomente, e o músculo clavotrapézio, posteriormente. Seguimos esse tronco até encontrar sua bifurcação em ramos menores, para confirmar ser essa estrutura o nervo facial, visto que não utilizamos estimulação intra-operatória deste nervo. O uso de estimulação intra-operatória do nervo facial foi descrito em apenas alguns estudos $2,18,19$.

Encontrado o tronco do nervo, realizamos a sua secção próxima ao forame mastóideo, porém em sete animais o ramo cervical posterior, provavelmente, divergia do tronco principal ainda junto ao forame mastóideo, dificultando o isolamento e secção desse tronco. Em quatro casos, realizamos a secção do tronco e do ramo e nos outros três, conseguimos isolar o tronco principal e seccioná-lo. Não encontramos citações a este respeito na literatura. Após a secção do tronco, os cotos foram aproximados com sutura epineural única, usando fio de nylon 9-0, por facilidade técnica. Embora a aproximação dos cotos tenha sido realizada por Fernandez et al. (1992 e 1995$)^{3,22}$ com fio de nylon 10-0 e por Guntinas-Lichius et al. (2001 e 2005) $)^{16,21}$ com nylon 11-0, Yian et al. (2001) em seu trabalho com coelhos utilizou nylon 8-0.

Por fim, realizamos o fechamento da pele com pontos separados de nylon 4-0. Já Fernandez et al. (1995) 22 usaram clipes metálicos no fechamento da pele, enquanto 
Bento \& Miniti (1989) ${ }^{12}$ realizaram, em seu estudo com gatos, fechamento da pele com catgut 2-0 em única camada e Mersa et al. (2000)² usaram pontos separados de nylon 4-0 para fechar a pele dos coelhos. Esse passo final do procedimento cirúrgico é bastante variável e também pouco citado na literatura.

A observação do comportamento dos animais envolvidos nos estudos de paralisia facial tem sido usada como um dos parâmetros para avaliar a regeneração do nervo facial. Estudos utilizando coelhos ${ }^{15}$, hamsters ${ }^{10}$ ou ratos $^{2,14,20}$ observaram o fechamento ocular, o reflexo de piscamento, a movimentação e posição das vibrissas. Em animais não-manipulados o reflexo de piscamento deve estar presente com fechamento ocular completo e simétrico, bem como a movimentação das vibrissas, que devem estar em posição anterior. Assim sendo, em animais com paralisia facial surgem sinais característicos que incluem a perda do reflexo de piscamento e da movimentação das vibrissas, que assumem posição posterior ${ }^{10,20,21}$. A partir da observação desses sinais, escalas distintas de avaliação da paralisia facial foram descritas.

Yian et al. (2001) ${ }^{15}$ desenvolveram uma escala para observação dos movimentos do lábio superior e da pálpebra de coelhos (submetidos à secção de ramos do nervo facial), com e sem estímulo (toque na testa e no nariz). Esta escala atribuía valores entre 0 e 3 , sendo 0 atribuído à ausência de movimento e 3, à movimentação normal; já os valores 1 e 2 destinaram-se a movimento leve e moderado, respectivamente. Byers et al. (1998) ${ }^{14}$ também descreveram uma escala subjetiva para observação dos parâmetros mencionados, em ratos pós-secção do nervo facial em seu canal. Esta escala variava entre 0 (nenhum movimento) e 100\% (movimento completo) e abordava, como a outra, olho e vibrissas conjuntamente. Já Gilad et al. (1996) ${ }^{20}$ avaliaram apenas a função das vibrissas e descreveram uma escala com variação de 0 a 4 , na qual observaram tremor das vibrissas, movimentação normal e posição das mesmas. Em seu estudo Mersa et al. (2000) ${ }^{2}$ observaram o fechamento ocular e o reflexo de piscamento, construíram uma escala com valores entre 0 e 2 , tendo como valor 0.5 a presença apenas de contração do músculo orbicular. Em seu estudo com gatos, Bento \& Miniti (1989) ${ }^{12}$ realizaram avaliação comportamental, atentando para o fechamento ocular através do reflexo de piscamento e para a ausência ou presença de movimento da face de forma simétrica ou assimétrica. Haldlock et al. $(2005)^{18}$ criaram uma escala com valores entre 0 e 1 , mas ao contrário desses estudos, aplicaram-na separadamente para avaliar movimentação das vibrissas e fechamento ocular. Justificaram esta separação com base na recuperação da função ocular e das vibrissas, que ocorreu em tempos distintos.

Elaboramos, então, uma escala de observação para avaliar a movimentação e posição das vibrissas e outra, com a mesma variação, para fechamento ocular e reflexo de piscamento, pois notamos recuperação assimétrica da função facial como mencionado por Haldlock et al. $(2005)^{18}$. Os parâmetros avaliados foram similares aos mencionados: ausência de movimento, tremor das vibrissas, movimentação normal e posição posterior ou anterior das mesmas; contração do músculo orbicular dos olhos, fechamento ocular incompleto e completo. A escala apresenta cinco pontuações (entre 1 e 5) e além da pontuação separada dos parâmetros, inclui uma somatória dos pontos de cada parâmetro distinto, de forma similar ao Sistema de Graduação Facial apresentado por Ross et al. ${ }^{23}$, em 1996 para avaliar clinicamente a recuperação facial em seres humanos. Desta forma é possível ter idéia da recuperação de um parâmetro isolado e de toda a face do animal, e também comparar animais de grupos distintos (em caso de trabalhos com grupo controle e grupos de estudo) de forma mais criteriosa.

Portanto, o rato permite que a observação dos seus movimentos oculares e da movimentação das vibrissas possa ser realizada e possibilita a elaboração de uma escala independente de avaliação que permite melhor análise destes parâmetros e da mímica facial como um todo. A abordagem do nervo facial em seu trajeto extratemporal, com secção e sutura, também é um procedimento que pode ser realizado de forma padronizada no rato, por este animal apresentar o tronco do nervo facial acessível e com variabilidade que não compromete esta abordagem.

\section{REFERÊNCIAS BIBLIOGRÁFICAS}

1. Choi D, Dunn LT. Facial nerve repair and regeneration: an overview of basic principles for neurosurgeons. Acta Neurochir (Wien) 2001;143:107-14.

2. Mersa B, Tiangco DA, Terzis JK. Efficacy of the "baby-sitter" procedure after prolonged denervation. J Reconstr Microsurg 2000;16(1):2735

3. Fernandez E, Pallini R, Marchese E, Lauretti L, Bozzini B, Sbriccoli A Reconstruction of pheripheral nerves: the phenomenon of bilateral reinnervation of muscles originally innervated by unilateral motoneurons. Neurosurgery 1992;30:364-9.

4. Guntinas-Lichius O, Neiss WF, Schulte E, Stennert E. Quantitative image analysis of the chromatolysis in rat facial and hypoglossal motoneurons following axotomy with and without reinnervation. Cell Tissue Res 1996;286:537-41.

5. Barrs DM. Facial nerve trauma: optimal timing for repair. Laryngoscope 1991;101:835-48.

6. Chen YS, Hsu CJ, Liu TC, Yanagihara N, Murakami S. Histological rearrangement in the facial nerve and central nuclei following immediate and delayed hypoglossal-facial nerve anastomosis. Acta Otolaryngol 2000;120:551-6.

7. Guntinas-Lichius O, Effenberger K, Angelov DN, Klein J, Streppel M, Stennert E, Neiss WF. Delayed rat facial nerve repair leads to accelerated and enhanced muscle reinnervation with reduced collateral axonal sprouting during a definite denervation period using a cross-anastomosis paradigm. Exp Neurol 2000;162:98-111.

8. Jergovic D, Stal P, Lidman D, Lindvall B, Hildebrand C. Changes in a rat facial muscle after facial nerve injury and repair. Muscle Nerve 2001;24:1202-12.

9. Kohmura E, Takamichi Y, Toshiki Y, Toshiyuki F, Norimasa K, Akihiko $S$ et al. BNDF atelocollagen mini-pellet accelerates facial nerve regeneration. Brain Res 1999;849:235-8. 
10. Jones KJ. Recovery from facial paralysis following crush injury of facial nerve in hamsters: differential effects of gender and androgen exposure. Exp Neurol 1993;121:133-8.

11. Mattson P, Aldskogius H, Sevensson M. Nimodipine-induced improved survival rate of facial motor neurons following intracranial transection of the facial nerve in the adult rat. J Neurosurg 1999;90:760-5.

12. Bento RF, Miniti A. Comparison between fibrin tissue adhesive, epineural suture and natural union in intratemporal facial nerve of cats. Acta Otolaryngol Suppl 1989;465:1-36.

13. Mattox DE, Felix H. Surgical anatomy of the rat facial nerve. Am J Otol 1987;8(1):43-7.

14. Byers JM, Clark KF, Thompson GC. Effect of pulsed eletromagnetic stimulation on facial nerve regeneration. Arch Otolaryngol Head and Neck Surg 1998;124:383-9.

15. Yian $\mathrm{CH}$, Paniello RC, Spector G. Inhibition of motor nerve regeneration in a rabbit facial nerve model. Laryngoscope 2001;111:786-91.

16. Guntinas-Lichius O, Irintchev A, Streppel M, Lenzen M, Grosheva M Wewetzer $\mathrm{K}$ et al. Factors limiting motor recovery after facial nerve transection in the rat: combined structural and functional analyses. Eur J Neurosci 2005;21:391-402.
17. Semba K, Egger D. The facial "motor" nerve of the rat: control of vibrissal movement and examination of motor and sensory components. J Comp Neurol 1986;247:144-58.

18. Hadlock TA, Heaton J, Cheney M, Mackinnon SE. Functional recovery after facial and sciatic nerve crush injury in the rat. Arch Facial Plast Surg 2005;7:17-20.

19. Terrel GS, Terzis JK. An experimental model to study the blink reflex. J Reconst Microsurg 1994;10(3):175-83.

20. Gilad VH, Tetzlaff G, Rabey JM, Gilad GM. Accelerated recovery following polyamines and aminoguanidine treatment after facial nerve injury in rats. Brain Res 1996;724:141-4.

21. Guntinas-Lichius O, Angelov DN, Tomov TL, Dramiga J, Neiss WF, Wewetzer K. Transplantation of olfactory ensheathing cells stimulates the collateral sprouting from axotomized adult rat facial motoneurons. Exp Neurol 2001;172:70-80.

22. Fernandez E, Pallini R, Marchese E, Lauretti L, Marca FL. Quantitative, morphological, and somatotopic nuclear changes after facial nerve regeneration in adult rats: a possible challenge to the "no new neurons" dogma. Neurosurgery 1995;37(3):456-63.

23. Ross BG, Fradet G, Nedzwlski JM. Development of a sensitive clinical facial grading system. Otolaryngol Head Neck Surg 1996;114:380-6. 